\title{
Small Intestine Metastasis from Endometrial Adenocarcinoma: A Case Report
}

\author{
Maryam M. Makki \\ Yousif H. Eltayeb \\ Rashid Hospital, Dubai Health Authority, Dubai, UAE
}

\section{Keywords}

Small bowel metastasis - Uterine metastasis - Melanoma metastasis

\section{Abstract}

Small bowel metastasis from malignant tumors is generally rare and underreported. Numerous cases might be overlooked. Direct spread is more frequent and comes from colon, ovary, stomach, and uterus. Less commonly, hematogenous distant metastasis from melanoma, lung, and breast is encountered. Melanoma represents the most frequent primary source, while uterus is a less common source. In this report, we present a case of small bowel metastatic tumor from uterus presenting with profound anemia and impending obstruction.

\section{(c) 2019 The Author(s)}

Published by S. Karger AG, Basel

\section{Introduction}

Endometrial cancer is the fourth most common cancer in females and is the most prevalent gynecological malignancy. The majority of cases are diagnosed at an early
Amir R. Saber

stage with the tumor confined to the uterus at the time of hysterectomy, which provides an excellent overall prognosis and a 5-year survival rate exceeding $70 \%$. Two histological types of endometrial cancer have been recognized as biologically distinct disease entities; type I and type II. Type I comprises endometroid carcinoma and its variants; type II consists of serous carcinoma, clear cell carcinoma, and carcinosarcoma. Endometroid carcinoma (type I) accounts for the majority of cases [1]. However, uterine serous carcinoma has a higher tendency for lymphovascular invasion in addition to intraperitoneal and extra-abdominal spread.

Typical sites of metastasis of endometrial carcinoma are pelvic and para-aortic lymph nodes, vagina, peritoneum, and lungs [2]. Atypical sites include bones, brain, abdominal wall, muscle, and intra-abdominal organs. The liver (7\%) is the most commonly involved intra-abdominal organ followed by the adrenal glands and spleen (1\%). Metastasis from endometrial cancer to small bowel is very rare [3].

In this report, we highlight an unusual site of metastasis of an endometrial adenocarcinoma to the small intestine.

\section{KARGER}

E-Mail karger@karger.com www.karger.com/dmj

\section{(C) 2019 The Author(s) \\ Published by S. Karger AG, Basel} NonCommercial-NoDerivatives 4.0 International License (CC BY NC-ND) (http://www.karger.com/Services/OpenAccessLicense). Usage and distribution for commercial purposes as well as any distribution of modified material requires written permission.
Yousif H. Eltayeb

Department of Surgery, Rashid Hospital

Dubai Health Authority

PO Box 4545, Dubai (UAE)

E-Mail yheltayeb@dha.gov.ae 


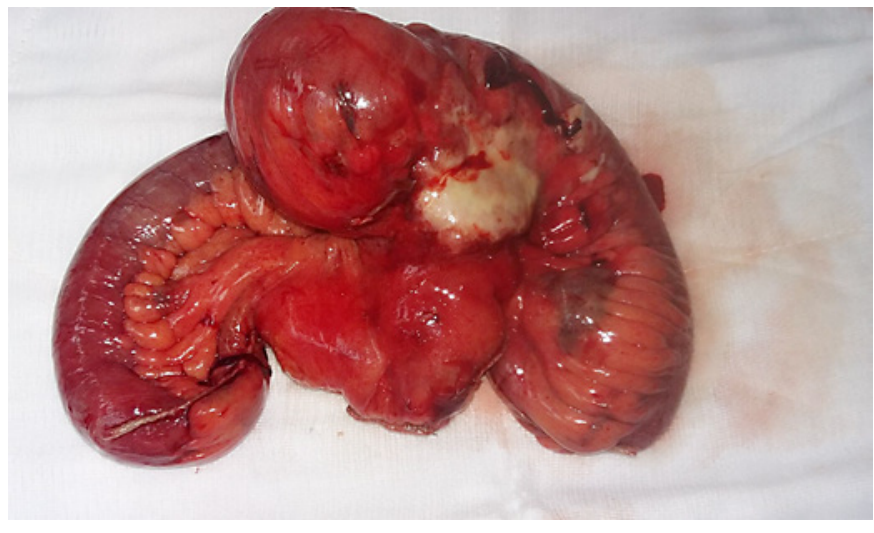

Fig. 1. Resected part of bowel showing hard exophytic tumor of 10 $\mathrm{cm}$ in size, about $90 \mathrm{~cm}$ from the DJ flexure.

\section{Case Presentation}

An 88-year-old female patient was admitted to the Medical Department of Rashid Hospital, Dubai (UAE) due to progressive drop in hemoglobin. The patient had a past surgical history of a total abdominal hysterectomy for endometrial carcinoma, which was performed 5 months prior to presentation. Patient hemoglobin dropped from 10.5 to $8 \mathrm{~g} / \mathrm{dL}$ over the past 2 months, occult blood stool test was positive, and she has received multiple blood transfusions. Upper and lower gastrointestinal (GI) endoscopy were requested and scheduled for her but were not done as the patient started complaining of abdominal pain that was not associated with nausea, vomiting, or constipation. On examination, the patient was conscious and alert. Her vitals were as follows: BP 115/60 mm Hg, pulse 60 beats/min, RR: 18, afebrile; her abdomen was not distended, with tenderness and rebound tenderness in the left upper quadrant and positive bowel sounds. Rectal examination was done, which was unremarkable with no bleeding or melena.

Her labs were as follows: WBC: $4.0 \times 10^{3} / \mu \mathrm{L}$, platelet count: 97 $\times 10^{9} / \mathrm{L}$, creatinine: $0.7 \mathrm{mg} / \mathrm{dL}$, prothrombin time: $23.3 \mathrm{~s}$; the rest of the lab investigations were within normal limits. CT of the abdomen and pelvis revealed a large necrotic mass lesion $(6.5 \times 5.6$ $\mathrm{cm}$ ) in relation to the mid-jejunal loops with mural wall thickening and a localized luminal narrowing with a large mesenteric exophytic component associated with significantly enlarged localized mesenteric nodes (Fig. 1). Exploratory laparotomy revealed a hard exophytic tumor of $10 \mathrm{~cm}$ in size, about $90 \mathrm{~cm}$ from the DJ flexure with omental and fibrinous adhesions to nearby bowel (Fig. 1). Resection of the affected segment and side-to-side anastomosis were performed. Histopathology revealed metastatic poorly differentiated adenocarcinoma involving the small bowel. The immunohistochemistry performed on the small bowel tumor showed positivity for CKAE1/AE3, ER, P53, and focally positive for PR. Chromogranin and CD56 immunohistochemical markers were negative. Morphology and immunohistochemical profile was consistent with metastatic adenocarcinoma of the small bowel in keeping with uterine primary (Fig. $2 \mathrm{a}-\mathrm{d}$ ).

\section{Discussion}

In spite of the fact that the small intestine constitutes the majority of the total mucosal surface of the GI tract, less than $2 \%$ of malignancies of the GI tract arise from the small bowel [4]. Adenocarcinoma is the most prevalent malignancy of the small intestine. However, metastatic involvement of the intestine is more common than primary small intestinal neoplasia. Extra-intestinal neoplasms can metastasize to the small bowel through hematogenous spread (breast, lung, and melanoma), direct invasion, or intraperitoneal seeding (colon, ovary, stomach, and uterus) [5]. Melanoma has the highest tendency to metastasize to the small intestine. However, small bowel metastasis from uterine cancer is a less common entity compared to metastasis from melanomas.

A number of mechanisms are believed to be the reason for the low rates of metastasis to the small intestine, which includes: (1) intensive lymphoid tissue and abundant secretions of IgA in the submucosal and mucosal layers; (2) high turnover rate of the small intestinal mucosa, which impedes tumorigenesis [6, 7].

Small-bowel cancer is typically asymptomatic in its early stages, but more than $90 \%$ of patients eventually develop symptoms as the disease progresses. This unfortunately reflects advanced disease [8].

For that reason, small bowel secondary tumors are often missed at initial presentation and the accurate diagnosis is delayed due to the nonspecific nature of symptoms. A significant delay between the onset of symptoms and diagnosis often occurs, averaging few months. It has been reported that the mean duration from the onset of the initial complaint to diagnosis is 7 months. This is in view of the fact that they generally progress in a surreptitious manner with nonspecific complaints, for instance, intermittent abdominal pain, anemia, or bleeding $[9,10]$.

Generally, nausea, vomiting, and intestinal obstruction are common presenting symptoms. Half of these patients undergo emergency surgery for intestinal obstruction as in this case. Abdominal pain and weight loss complicate the clinical presentation, while GI bleeding is less common [11]. There are very few published series on small bowel secondary neoplasms, which might be due to underreporting as cases might be overlooked due to varying presentation of the individual histologic subtypes [12, 13]. However, it does appear that adenocarcinomas are more frequently associated with pain and obstruction when compared to sarcomas and carcinoids. Sarcomas (GIST) present more commonly with acute GI bleeding [14]. 

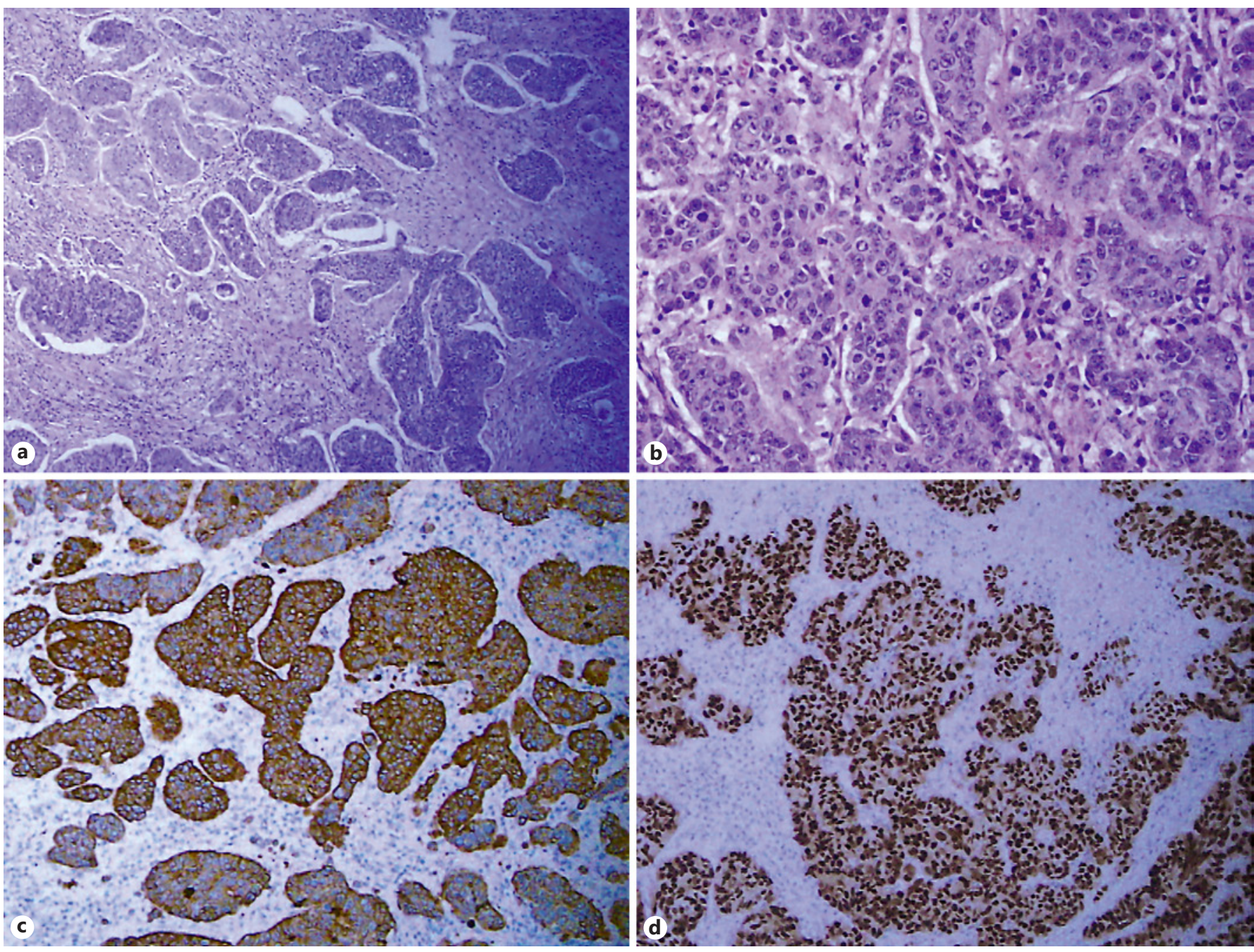

Fig. 2. Histopathology findings. a S17-254-10×: $10 \times$ is the magnification. The picture shows a low-power view of the tumor showing tumor arranged in nests and broad trabeculae. b S17-254-40x (three pictures): $40 \times$ is the high-power magnification. The picture shows sheets of tumor cells showing high N/C ratio with pleomorphic hyperchromatic nuclei containing prominent nucleoli. Brisk

\section{Conclusion}

Small bowel metastasis is a rare entity. Metastases from the uterus are less common compared to melanoma and generally underreported. Due to bizarre symptoms, a high index of suspicion and screening of patients at risk is to be recommended to avoid delaying the diagnosis.

mitosis is identified with areas of desmoplastic stromal response. c S17-254-cytokeratin: epithelial immunostain positivity confirming epithelial nature of malignancy. d S17-254-estrogen receptor and P53: both immunostains show nuclear positivity in tumor cells.

\section{Acknowledgement}

The authors are greatly indebted to Mr. B.B., Specialist Medical Training Section/DHA Library, Medical Education and Research Department for the great effort and help for preparing the manuscript.

\section{Statement of Ethics}

Signed consent was taken from the guardian.

Dubai Med J 2019;2:117-120
DOI: $10.1159 / 000502974$

DOI: $10.1159 / 000502974$ 


\section{Disclosure Statement}

The authors have nothing to disclose

\section{Funding Sources}

No funding was required.

\section{References}

1 Cheung DY, Choi MG. Current advance in small bowel tumors. Clin Endosc. 2011 Sep; 44(1):13-21.

2 Xynopoulos D, Mihas AA, Paraskevas E, Dimitroulopoulos D, Heuman DM. Small bowel tumors. Ann Gastroenterol. 2002; 15(1):18-35.

3 Sugimoto T, Mike M, Abe M, Kano N. Small bowel metastasis of uterine cervical adenocarcinoma. BMJ Case Rep. 2013 Aug;2013 aug26 1:007896.

4 Yu X, Wang Z, Zhang Z, Liu Y, Huang J. Postoperation of cervical cancer with intestine metastasis: a case report and literature review. World J Surg Oncol. 2016 Jan;14(1):2.

5 Blazer DG 3rd, Ramirez PT, Wang H, Fleming JB. Distal pancreatectomy for isolated metastasis of endometrial carcinoma to the pancreas. JOP. 2008 Jan;9(1):56-60.

\section{Author Contributions}

The authors have equally contributed in collecting data and preparation of the manuscript.
6 Roma AA, Rybicki LA, Barbuto D, Euscher E Djordjevic B, Frauenhoffer E, et al. Risk factor analysis of recurrence in low-grade endometrial adenocarcinoma. Hum Pathol. 2015 Oct; 46(10):1529-39.

7 Kurra V, Krajewski KM, Jagannathan J, Giardino A, Berlin S, Ramaiya N. Typical and atypical metastatic sites of recurrent endometrial carcinoma. Cancer Imaging. 2013 Mar; 13(1):113-22.

8 Awrich AE, Irish CE, Vetto RM, Fletcher WS. A twenty-five year experience with primary malignant tumors of the small intestine. Surg Gynecol Obstet. 1980 Jul;151(1):9-14.

9 Zollinger RM Jr, Sternfeld WC, Schreiber H. Primary neoplasms of the small intestine. Am J Surg. 1986 Jun;151(6):654-8.
10 Ouriel K, Adams JT. Adenocarcinoma of the small intestine. Am J Surg. 1984 Jan;147(1): 66-71.

11 Ebert PA, Zuidema GD. Primary tumors of the small intestine. Arch Surg. 1965 Sep;91(3): $452-5$.

12 Bauer RL, Palmer ML, Bauer AM, Nava HR, Douglass HO Jr. Adenocarcinoma of the small intestine: 21-year review of diagnosis, treatment, and prognosis. Ann Surg Oncol. 1994 May;1(3):183-8.

13 Garcia Marcilla JA, Sanchez Bueno F, Aguilar J, Parrilla Paricio P. Primary small bowel malignant tumors. Eur J Surg Oncol. 1994 Dec; 20(6):630-4

14 Adler SN, Lyon DT, Sullivan PD. Adenocarcinoma of the small bowel. Clinical features, similarity to regional enteritis, and analysis of 338 documented cases. Am J Gastroenterol. 1982 May;77(5):326-30. 